\title{
Behavior of Axially Loaded CFRP Confined Large-Scale Capsule-Shaped RC Short Columns with Higher Cross-Sectional Aspect Ratio
}

\author{
Abd El Rahman Megahid Ahmed ${ }^{1}$, Omar Ahmed Farghal ${ }^{1}$, Walied Ahmed Bazar ${ }^{2, *}$ \\ ${ }^{1}$ Civil Engineering Department, Faculty of Engineering, Assiut University, Assiut, Egypt \\ ${ }^{2}$ Civil Engineering Department, Hadhramout University, Hadhramout, Yemen
}

Email address:

waleedbazar@gmail.com (W. A. Bazar)

${ }^{*}$ Corresponding author

\section{To cite this article:}

Abd El Rahman Megahid Ahmed, Omar Ahmed Farghal, Walied Ahmed Bazar. Behavior of Axially Loaded CFRP Confined Large-Scale Capsule-Shaped RC Short Columns with Higher Cross-Sectional Aspect Ratio. Journal of Civil, Construction and Environmental Engineering. Vol. 3, No. 3, 2018, pp. 64-77. doi: 10.11648/j.jccee.20180303.13

Received: July 4, 2018; Accepted: July 12, 2018; Published: August 7, 2018

\begin{abstract}
This paper aimed to experimentally and analytically investigate the behavior of reinforced concrete (RC) short capsule-shaped columns confined with carbon fiber-reinforced polymer (CFRP) sheets. The efficiency of FRP-confined strengthening system depends mainly on different encountered parameters such as the FRP confinement ratio, shape and size of cross-section, and cross sectional aspect ratio of non-circular columns. The effects of varying the aspect ratio $(\mathrm{h} / \mathrm{b}=2,2.5,3$ and 4), FRP confinement ratio (number of FRP layers), and FRP-wrapping configuration (full and partial system) are examined in this study. The experiment results showed that the efficiency of FRP confined system was proven to be lower with higher aspect ratio than that with the lower aspect ratio. Confinement by CFRP sheets enhances the performance of capsule-shaped RC columns subjected to axial compressive loads, and it is an efficient technique to improve the strength and ductility of capsule shaped RC columns regardless the cross sectional aspect ratio and the type of confinement. Analytical model was proposed by the authors to predict the axial load carrying capacity of short capsule-shaped reinforced concrete columns. The proposed model is compared with the existing model, showing good agreement with the experimental results and it is improved performance and gives reasonable predictions of load carrying capacity of FRP-confined columns.
\end{abstract}

Keywords: Capsule-Shaped, Axial Load, Aspect Ratio, Short Column, CFRP

\section{Introduction}

Wrapping of concrete columns with CFRP sheets is considered as an efficient strengthening technique. The efficiency of FRP-confined technique depends mainly on the shape cross-section. In case of FRP-confined rectangular columns, the cross-sectional aspect ratio effects significantly on the efficiency of this strengthening technique. In the updated version of the ACI 440.2R-08 [1], the limitation of the aspect ratio of FRP-confined rectangular columns is extended from 1.5 to 2.0 as a limit to apply this strengthening technique, and the effect of the cross-sectional aspect ratio (h/b) was added as a shape factor for noncircular cross sections columns confined by FRP. One approach for improving the effectiveness of FRP jackets for rectangular columns is to perform shape-modification of the column cross-section into an oval, elliptical, capsule-shaped or circular cross-section. Columns with rectangular cross-section can be modified to capsule shape by adding semi-circular to shorter sides of columns to improve the confinement effectiveness of FRP sheets. A limited number of experimental studies have been performed on large-scale FRP-confined reinforced concrete columns having a capsule shape cross section with a higher aspect ratio. More researches focused on FRP-confined rectangular columns subjected to axial loading [2-8]. It is concluded that the confinement increased the strength and ductility of the columns. Also, previous researches attest the significant effect of the cross-sectional aspect ratio. Moreover, the efficiency decreased considerably as aspect ratio increased. 
However, Triantafillou et al, [9], found that wrapping with FRP sheets increased the axial strength of rectangular reinforced concrete columns even with aspect ratios higher than 3.0. Therefore, the confinement effectiveness of FRP composites for non-circular columns with higher cross sectional aspect ratios and the behavior of these types of columns should be further evaluated.

On the other side, few researchers $[10,11]$ investigated the behavior of FRP-confined capsule-shaped columns, it has been found that the increase in axial load capacity of FRP-confined capsule shaped columns was greater than the corresponding columns. A test program by Tan et al, [11] was conducted on FRP-confined capsule-shaped plain concrete columns with cross-sectional aspect ratios varied from one to four and confined with CFRP sheets. The columns were tested under monotonically increasing axial load. Test results showed significant enhancement in confined compressive strength of columns by $143 \%, 72 \%, 22 \%$ and $28 \%$ for column's cross- sectional aspect ratios of 1,2, 3 and 4 respectively. FRP-confined columns with higher cross-sectional aspect ratios showed an insignificant increase in axial strength. This can be attributed to the lower confining pressure and smaller confined concrete area.

\section{Experimental Program}

\subsection{Materials and Methods}

Ordinary Portland cement was used throughout the program for making the concrete, the water - cement ratio was 0.52 to have a slump of $80 \pm 10 \mathrm{~mm}$. The fine aggregate used was natural siliceous sand with specific gravity of 2.50 and unit weight of $15 \mathrm{KN} / \mathrm{m}^{3}$. The coarse aggregate was crushed gravel of $20 \mathrm{~mm}$ maximum nominal size, with specific gravity of 2.65 and unit weight of $15 \mathrm{KN} / \mathrm{m}^{3}$. The concrete mix contents by weight for one cubic meter of concrete are given in Table 1 .

Table 1. The constituent materials per cubic meter of concrete.

\begin{tabular}{llll}
\hline Cement (kg) & Fine agg. (kg) & Coarse agg. (kg) & Water (liter) \\
\hline 375 & 613 & 1226 & 195 \\
\hline
\end{tabular}

The different columns were reinforced with high tensile steel deformed bars of grade 400/600 and diameter $12 \mathrm{~mm}$ as longitudinal steel. Mild steel plain bars of grade 240/350 and diameter $6 \mathrm{~mm}$ was used as internal closed stirrups for the different columns. Yield/proof stress and tensile strength are 421 and $678 \mathrm{MPa}$ for $12 \mathrm{~mm}$ diameter bars and 266 and 389 MPa for $6 \mathrm{~mm}$ diameter bars.

The external reinforcement was a CFRP sheet [12] of $0.131 \mathrm{~mm}$ equivalent dry fiber thickness $\left(t_{f}\right)$. The ultimate tensile $\operatorname{strain}\left(\varepsilon_{\mathrm{fult}}\right)$, E-modulus $\left(E_{f}\right)$, and Tensile strength of CFRP sheet without polymeric matrix are (in accordance with the manufacturer) $1.8 \%, 238000 \mathrm{MPa}$, and $4300 \mathrm{MPa}$, respectively. The resin used for the completion of CFRP sheets has flexural E-modulus and tensile strength of $3800 \mathrm{MPa}$ and $30 \mathrm{MPa}$, respectively. For different column specimens, steel moulds were used for casting the specimens vertically.

Axial compressive loads were applied to the column specimens by using a universal testing machine of $5000 \mathrm{KN}$ capacity. Two linear variable differential transducers (LVDTs) were attached to the lower plate (moving head) of the testing machine to measure the mean axial shortening of the columns. The LVDT data were used to calculate the mean axial concrete strain. Also, two vertical electrical strain gages and four transverse electrical strain gages were placed on the surface of concrete at mid-height of the specimens in case of control columns to measure the vertical and transverse strains induced in the concrete. Moreover, in order to measure the transverse strain (hoop strain) induced in the CFRP jacket during loading, four electrical strains were attached to the surface of CFRP in the hoop direction at mid-height of the strengthened specimens. All instrumental equipment were connected to a data-logger system (TDS-150) which was connected with computer to record the values of strains, load cell readings, and LVDT deformations during testing at every one second.

\subsection{Details of Tested Columns}

Sixteen normal reinforced concrete rectangular columns were casted with different cross-sectional aspect ratios $(\mathrm{h} / \mathrm{b}=1,1.5,2$, and 3$)$, where ( $\mathrm{h} ")$ is the length of straight portion of the longer side of the original section, as shown in Figure 1. Two semi-circular segments of normal concrete were added on the two short ends of the rectangular section to form a capsule-shape column, and then each column was wrapped transversely with CFRP sheets. The diameter of these semicircular segments is same as the width of the square and rectangular sections. The cross-sectional aspect ratios of rectangular section $(\mathrm{h} / \mathrm{b}=1,1.5,2$, and 3$)$ will become a capsule shaped with aspect ratio $(\mathrm{h} / \mathrm{b}=2,2.5,3$, and 4) respectively, after adding the two semi-circular segmental pieces, see Figures $1 \& 2$. The capsule shape columns were designated as B0-m for unconfined columns. However, the designation were BFn-m and BPn-m for fully and partially confined columns, where (F) refers to fully confined and (P) refers to partially confined, $(\mathrm{m})$ gives the aspect ratio $(\mathrm{h} / \mathrm{b})$, and (n) denotes the number of layers of wrapping CFRP sheets The specimens are classified into four series as shown in Table 2 and Figure 1. The first series was the reference control columns (B0-m) unconfined capsule shaped with different cross-sectional aspect ratios (m). The second series of capsule shape columns (BF1-m) were fully wrapped with one layer of CFRP for different cross-sectional aspect ratios (m). The third series of columns (BF2-m) is same as the second series of columns (BF1-m) but wrapped with two layers of CFRP sheets. The fourth series of columns (BP2-m) were partially confined with two layers of CFRP sheets with same percentage of confinement as full wrapping with one layer of CFRP sheet.

The smallest dimension of cross-section (shorter side) $b$ of different column specimens equals $150 \mathrm{~mm}$. The different tested specimens are short columns with constant slenderness ratio $\mathrm{H} / \mathrm{b}$ of 6 , where $\mathrm{H}(=900 \mathrm{~mm})$ is the height of the column, which was kept constant for the different columns. The percentage of internal longitudinal steel reinforcement is also kept constant and equal to $\mu \mathrm{s}(\approx 1.8 \%)$ and the percentage of 
internal lateral reinforcement $\mu_{\mathrm{v}}(=0.45 \%)$ was kept constant for all column specimens. The mean compressive strength for standard cube after 28 days for the different tested columns were listed in Table 2.
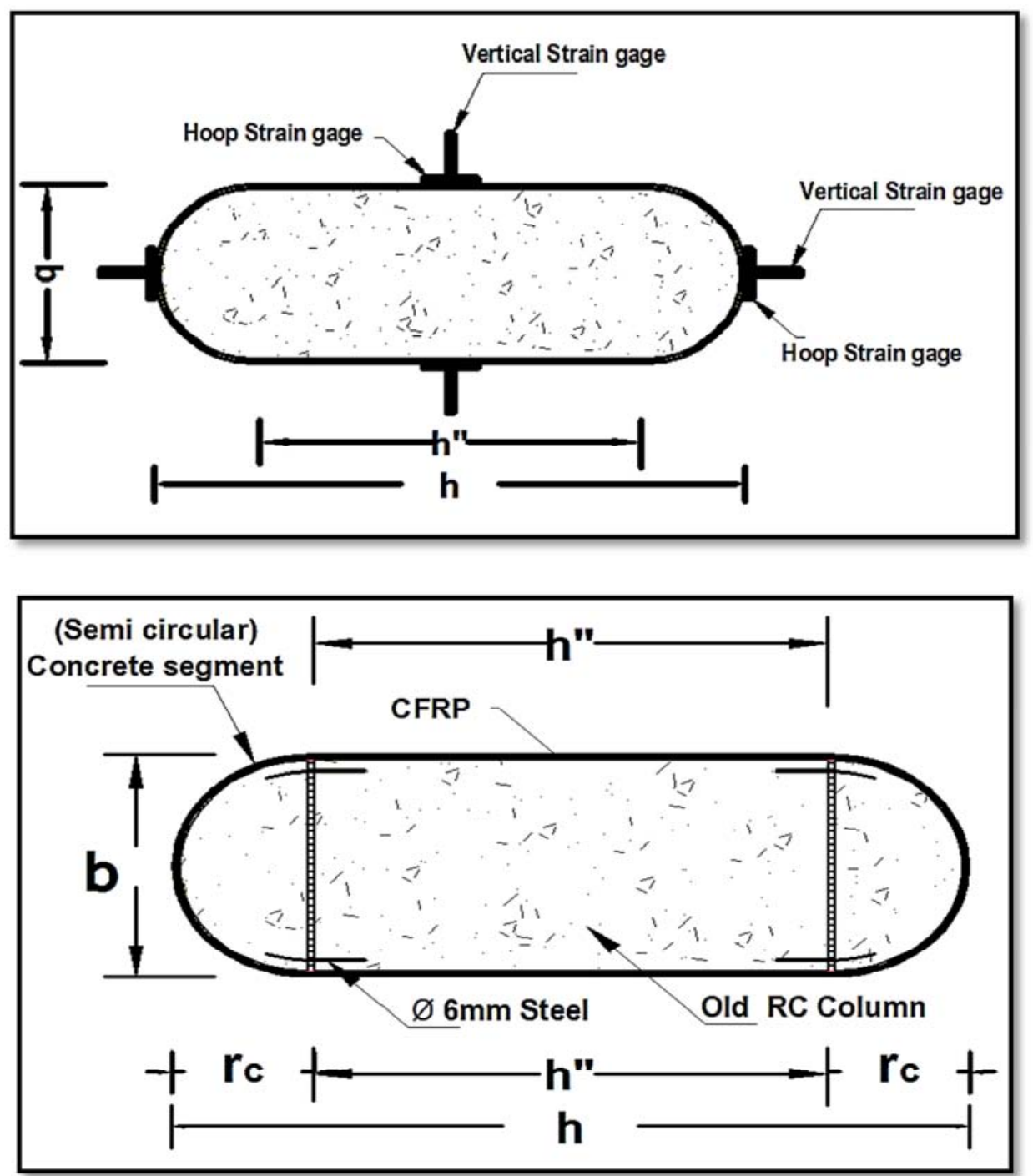

Figure 1. Geometrical details of tested columns with strain gauge locations.

Table 2. Details and data of tested capsule-shaped columns.

\begin{tabular}{|c|c|c|c|c|c|c|c|c|}
\hline \multirow{3}{*}{ Column No. } & \multirow{2}{*}{$\begin{array}{l}\text { Concrete } \\
\text { Strength }\end{array}$} & \multirow{2}{*}{\multicolumn{2}{|c|}{ Columns Dimensions }} & \multicolumn{2}{|c|}{ Internal Reinforcement } & \multirow{2}{*}{\multicolumn{3}{|c|}{ Confinement* }} \\
\hline & & & & Longitudinal & Lateral & & & \\
\hline & $f_{c u}$ (MPa) & $\mathbf{b} \times \mathbf{h}(\mathbf{m m})$ & $\mathbf{h} / \mathbf{b}$ & As & $\mathrm{S}\left(\mu_{\mathrm{v}}=0.45 \%\right)$ & $b_{f}(\mathbf{m m})$ & $S_{f}(\mathrm{~mm})$ & $\mu_{f}(\%)$ \\
\hline B0-2 & 31.2 & \multirow{4}{*}{$\begin{array}{l}150 \times 300 \\
\left(h^{\prime \prime}=150\right)\end{array}$} & \multirow{4}{*}{2} & \multirow{4}{*}{$\begin{array}{l}6 \Phi 12 \mathrm{~mm} \\
\left(\mu_{s} \approx 1.8 \%\right)\end{array}$} & \multirow{4}{*}{$\begin{array}{l}1 \varnothing 6 \mathrm{~mm} \\
@ 120 \mathrm{~mm} \\
(\mu \mathrm{v}=0.45 \%)\end{array}$} & & & \\
\hline BP-2 & 33 & & & & & 70 & 140 & 0.25 \\
\hline BF1-2 & 32.9 & & & & & $\ldots$. & $\ldots$ & 0.25 \\
\hline BF2-2 & 34.4 & & & & & $\ldots$ & $\ldots$ & 0.5 \\
\hline B0-2.5 & 31.2 & \multirow{4}{*}{$\begin{array}{l}150 \times 375 \\
\left(h^{\prime \prime}=225\right)\end{array}$} & \multirow{4}{*}{2.5} & \multirow{4}{*}{$\begin{array}{l}8 \Phi 12 \mathrm{~mm} \\
\left(\mu_{s} \approx 1.8 \%\right)\end{array}$} & \multirow{4}{*}{$\begin{array}{l}1 \varnothing 6 \mathrm{~mm} \\
@ 110 \mathrm{~mm} \\
(\mu \mathrm{v}=0.45 \%)\end{array}$} & $\ldots$. & & $\ldots$ \\
\hline BP-2.5 & 33 & & & & & 70 & 140 & 0.235 \\
\hline BF1-2.5 & 32.9 & & & & & $\ldots$. & $\ldots$ & 0.235 \\
\hline BF2-2.5 & 34.4 & & & & & $\ldots$. & $\ldots$ & 0.47 \\
\hline B0-3 & 31.2 & \multirow{4}{*}{$\begin{array}{l}150 \times 450 \\
\left(h^{\prime \prime}=300\right)\end{array}$} & \multirow{4}{*}{3} & \multirow{4}{*}{$\begin{array}{l}10 \Phi 12 \mathrm{~mm} \\
\left(\mu_{s} \approx 1.8 \%\right)\end{array}$} & \multirow{4}{*}{$\begin{array}{l}2 \emptyset 6 \mathrm{~mm} \\
@ 160 \mathrm{~mm} \\
(\mu \mathrm{v}=0.45 \%)\end{array}$} & $\ldots$ & $\ldots$ & $\ldots$ \\
\hline BP-3 & 33 & & & & & 70 & 140 & 0.224 \\
\hline BF1-3 & 32.9 & & & & & $\ldots$. & $\ldots$ & 0.224 \\
\hline $\mathrm{BF} 2-3$ & 34.4 & & & & & $\ldots$. & $\ldots$ & 0.448 \\
\hline B0-4 & 31.2 & \multirow{3}{*}{$\begin{array}{l}150 \times 600 \\
\left(h^{\prime \prime}=450\right)\end{array}$} & \multirow{3}{*}{4} & \multirow{3}{*}{$\begin{array}{l}14 \Phi 12 \mathrm{~mm} \\
\left(\mu_{s} \approx 1.8 \%\right)\end{array}$} & \multirow{3}{*}{$\begin{array}{l}2 \varnothing 6 \mathrm{~mm} \\
\text { (a) } 130 \mathrm{~mm} \\
(\mu \mathrm{v}=0.45 \%)\end{array}$} & $\ldots$. & $\ldots$. & $\ldots$ \\
\hline BP-4 & 33 & & & & & 70 & 140 & 0.21 \\
\hline BF1-4 & 32.9 & & & & & $\ldots$. & $\ldots$ & 0.21 \\
\hline
\end{tabular}

$b_{f}$ is the width of the CFRP strips, $S_{f}$ is center to center spacing of the CFRP strips, $\mu_{f}$ FRP confinement ratio, ${ }^{*}$ see Figure (13). 


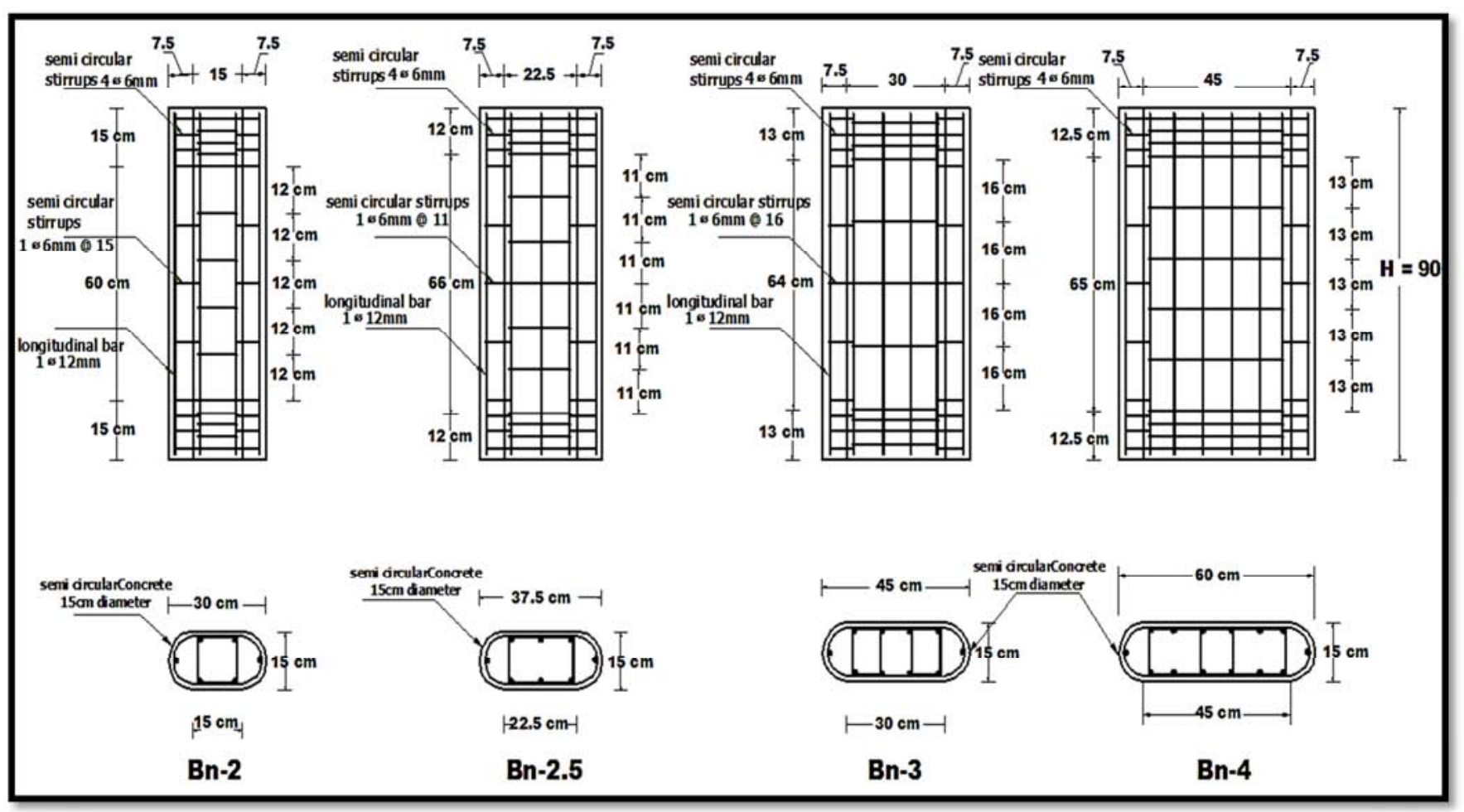

Figure 2. Details of reinforced concrete tested columns.

\section{Experimental Results and Discussion}

The test results of the different tested columns in terms of maximum load $\left(P_{u}\right)$, axial stress of FRP-confined columns $f_{c c}\left(=P_{u} / A_{g}\right)$ which is the maximum load over the cross sectional area, $P_{u, \text { conf }}$ and $P_{u, u c o n f}$ are the maximum axial load of confined and corresponding unconfined tested columns respectively. The ratio $\left(P_{u, \text { conf }} / P_{u, \text { unconf }}\right)$ is defined as a strengthening ratio, and the gained strength equals
$\left(P_{u, \text { conf }}-P_{u, \text { unconf }} / P_{u, \text { unconf }}\right) \times 100 \quad, \quad$ mean $\quad$ axial strain $\varepsilon_{\mathrm{c} \text { mean }}$ corresponding to maximum load. Moreover, the results includes FRP-hoop strains at maximum load (at mid-height) $\varepsilon_{\text {fmax }}$. Also, the hoop strain efficiency factor or the jacket efficiency factor $\left(\mathrm{K}_{\varepsilon}=\varepsilon_{\mathrm{fmax}} / \varepsilon_{\mathrm{fult}}\right)$ is the ratio of the maximum hoop strain $\varepsilon_{\mathrm{fmax}}$ over the FRP ultimate tensile strain $\varepsilon_{f \text { ult }}(=1.8 \%)$ are given in Table 3. Maximum hoop CFRP strains.

Table 3. Experimental results of capsule-shaped tested columns.

\begin{tabular}{|c|c|c|c|c|c|c|c|c|c|}
\hline \multirow[b]{2}{*}{ Column No. } & \multirow[b]{2}{*}{$\mathbf{h} / \mathbf{b}$} & \multirow[b]{2}{*}{$\begin{array}{l}\text { No. } \\
\text { Layers }\end{array}$} & \multicolumn{5}{|c|}{ Axial Stress \& Strains } & \multicolumn{2}{|c|}{ Max. hoop CFRP Strains } \\
\hline & & & $\begin{array}{l}P_{u} \\
(\mathbf{K N})\end{array}$ & $\begin{array}{l}f_{c c} \\
\text { (MPa) }\end{array}$ & $\frac{P_{u \text { conf }}}{P_{\text {u unconf }}}$ & $\begin{array}{l}\varepsilon_{c c} \\
(\%)\end{array}$ & $\frac{\varepsilon_{c c}}{\varepsilon_{c o}}$ & $\begin{array}{l}\varepsilon_{f \max } \\
(\%)\end{array}$ & $\frac{\varepsilon_{f \max }}{\varepsilon_{f u l t}}\left(K_{\varepsilon}\right)$ \\
\hline B0-2 & \multirow{4}{*}{2} & 0 & 1155 & 28.80 & 1.00 & 4.90 & 1.00 & 1.20 & $\ldots \ldots$ \\
\hline BP-2 & & 2 & 1414 & 35.26 & 1.22 & 8.10 & 1.65 & 4.26 & 0.24 \\
\hline BF1-2 & & 1 & 1658 & 41.33 & 1.44 & 10.07 & 2.06 & 5.48 & 0.30 \\
\hline BF2-2 & & 2 & 1959 & 48.85 & 1.70 & 12.54 & 2.56 & 7.17 & 0.40 \\
\hline BP-2.5 & \multirow{3}{*}{2.5} & 2 & 1655 & 32.20 & 1.16 & 6.42 & 1.29 & 2.25 & 0.13 \\
\hline BF1-2.5 & & 1 & 1884 & 36.65 & 1.32 & 8.03 & 1.61 & 3.36 & 0.19 \\
\hline BF2-2.5 & & 2 & 2175 & 42.32 & 1.53 & 9.99 & 2.01 & 4.69 & 0.26 \\
\hline B0-3 & \multirow{4}{*}{3} & 0 & 1651 & 26.38 & 1.00 & 5.01 & 1.00 & 1.63 & $\ldots \ldots$ \\
\hline BP-3 & & 2 & 1816 & 29.01 & 1.10 & 6.31 & 1.26 & 2.03 & 0.11 \\
\hline BF1-3 & & 1 & 2043 & 32.63 & 1.24 & 7.92 & 1.58 & 2.77 & 0.15 \\
\hline BF2-3 & & 2 & 2326 & 37.16 & 1.41 & 9.45 & 1.89 & 3.33 & 0.19 \\
\hline BP-4 & \multirow[t]{3}{*}{4} & 2 & 2255 & 26.50 & 1.05 & 5.65 & 1.12 & 1.60 & 0.09 \\
\hline BF1-4 & & 1 & 2399 & 28.19 & 1.12 & 7.50 & 1.49 & 1.99 & 0.11 \\
\hline BF2-4 & & 2 & 2523 & 29.64 & 1.18 & 8.95 & 1.78 & 2.67 & 0.15 \\
\hline
\end{tabular}




\subsection{Failure Modes}

The cross sectional aspect ratio showed insignificant effect on the obtained failure mode of the tested columns. The control columns failed due to crushing concrete in a typical shear, compression failure as shown in Figure 3. The concrete crushing occurred at middle third of the columns height, accompanied with the splitting of concrete cover in that zone.

The most typical failure mechanism of fully confined column specimens was the rupture of CFRP sheets accompanied with crushing of concrete in that zone, as shown in Figure 3. The rupture of CFRP occurred at or near

the corner and located at middle- third of the column's height. Failure of the confined specimens occurred suddenly without warning.

At a stress level corresponding to the unconfined concrete strength, the partially wrapped column specimens (BP-2, BP-2.5, BP-3 and BP-4) showed fine cracks at free spacing zone between FRP strips, as shown in Figure 3. The failure was observed due to crushing concrete at the free spacing between FRP strips. These specimens then failed explosively, due to FRP sheets rupture at the middle-third height, as shown in Figure 3.

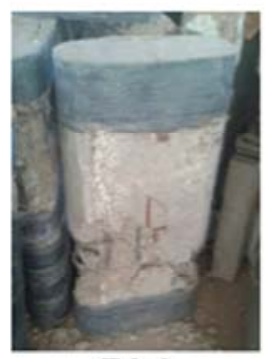

B0-3

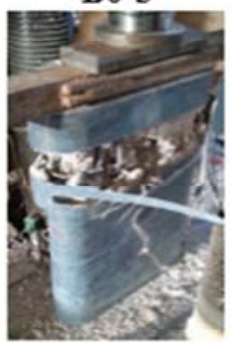

BF2-3

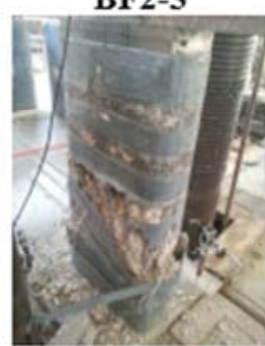

BP-3

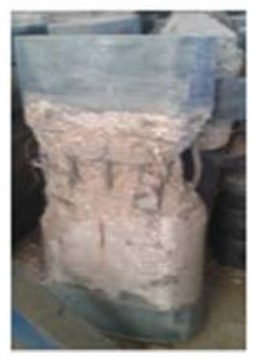

B0-4

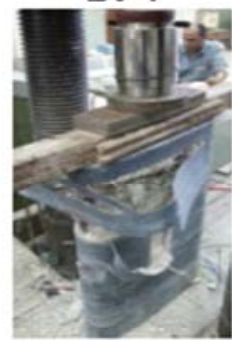

BF2-4

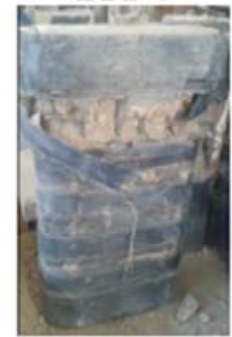

BP-4

Figure 3. Failure modes of tested columns.

\subsection{Axial Load Capacity and Gained Strength}

The compressive strength of the FRP-confined columns enhanced significantly in comparison with corresponding control columns. To estimate the improvement in the axial load capacity due to confinement, the ratio of maximum load of the confined column to their counterpart control column $\left(P_{u, \text { conf }} / P_{u, \text { unconf }}\right)$ was defined as strengthening ratio. From Table 3, it can be seen that the FRP-confinement of capsule shape columns increases the compressive strength. In addition, as the increase FRP-confinement ratio (increase in the number of FRP layers), the gained strength increase with respect to unconfined columns.

For aspect ratio of 2 , the values of strengthening ratio $\left(P_{u, \text { conf }} / P_{u, \text { unconf }}\right)$ were 1.44 and 1.70 for one layer and two layers respectively, However, those of higher aspect ratio $(\mathrm{h} / \mathrm{b}=4)$ showed much smaller 1.12 and 1.18 respectively. In general, as the FPR confinement ratio increase the compressive strength increase, particularly in case of lower aspect ratio and fully confined columns. By other words, the gained strength increase as the aspect ratio decrease. On the contrary strengthening ratio, there is insignificant gained strength for columns with higher aspect ratio $(h / b=4)$ for one and two layers. Figure 4 shows the variation of gained strength versus cross-sectional aspect ratios $(\mathrm{h} / \mathrm{b})$ of columns confined with zero, one, and two layers of CFRP sheets. For fully confined the largest value of gained strength $(=70 \%)$ was occurred in capsule shaped column specimens of $h / b=2$ (BF2-2) while very low values equals $12 \%$ were found in capsule shaped columns of higher aspect ratio of $h / b=4$ 
(BF1-4). The gained strength of FRP-confined columns are direct proportional to the number of FRP layer and inversely proportional with the cross-sectional aspect ratio. FRP-confined columns with higher aspect ratios $(\mathrm{h} / \mathrm{b}>3)$ showed insignificant increase in axial strength. This can be attributed to the lower confining pressure, non-uniform stress distribution and lower confined area of concrete. It is worth to mention that according to a previous study by the authors (Megahid et al, 2018) on the FRP-confined rectangular columns, for certain aspect ratio and same number of layers, FRP-confined capsule-shaped columns was showed a higher gained strength in comparison to FRP-confined rectangular columns due to higher effective confined area and the higher level of confinement of FRP-confined capsule-shaped columns.

For all cases of confinement, the fully confined columns showed a higher gained strength in comparison with the corresponding partially confined columns. For the same FRP confinement ratio the gained strength for fully confined columns were $44 \%, 32 \%, 24 \%$, and $12 \%$ when aspect ratios were 2, 2.5, 3 and 4 respectively, see Figure (5-a), however, lower improvements for partially confined ones which showed gained strength of $22 \%, 16 \%, 10 \%$ and $5 \%$ when

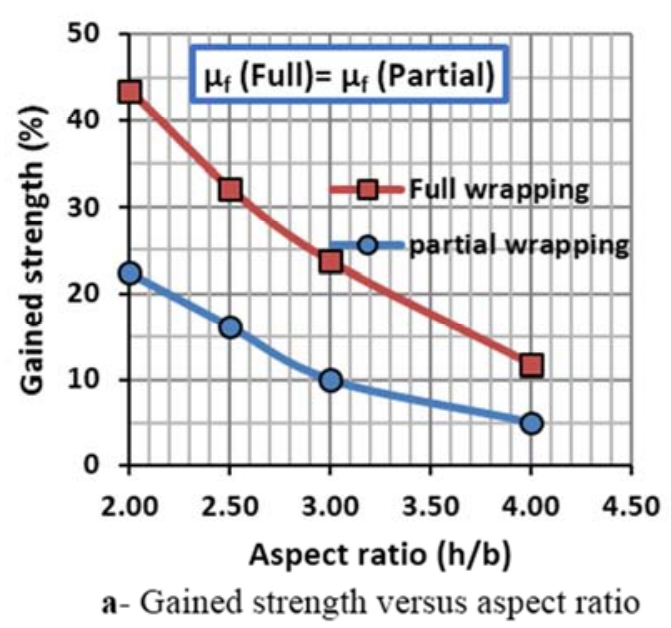

aspect ratios were 2, 2.5, 3 and 4 respectively. Therefore, partially confined system is not recommended to be applied for capsule shape columns particularly, for higher aspect ratio $(\mathrm{h} / \mathrm{b} \geq 2.5)$. For partially FRP-confined capsule shaped columns, the load carrying capacity decreased as aspect ratio increased: the improvement in the load carrying capacity were $22 \%, 16 \%, 10 \%$ and $5 \%$ when the aspect ratio were 2 , $2.5,3$ and 4 respectively.

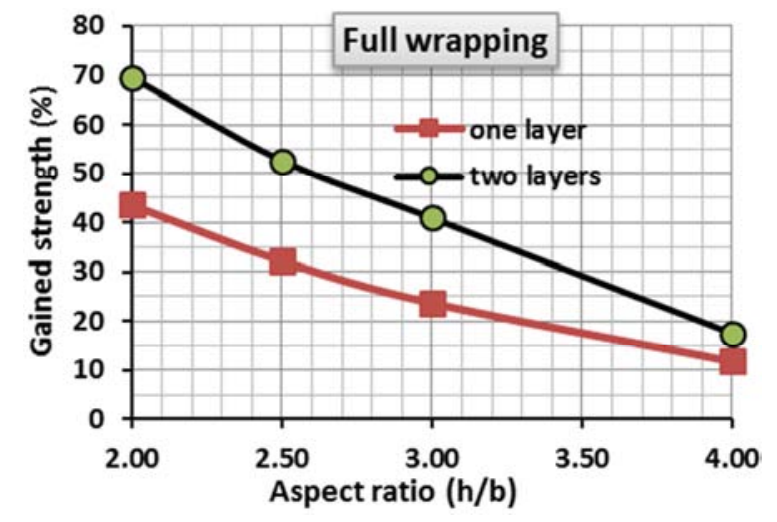

Figure 4. Gained strength versus aspect ratio.

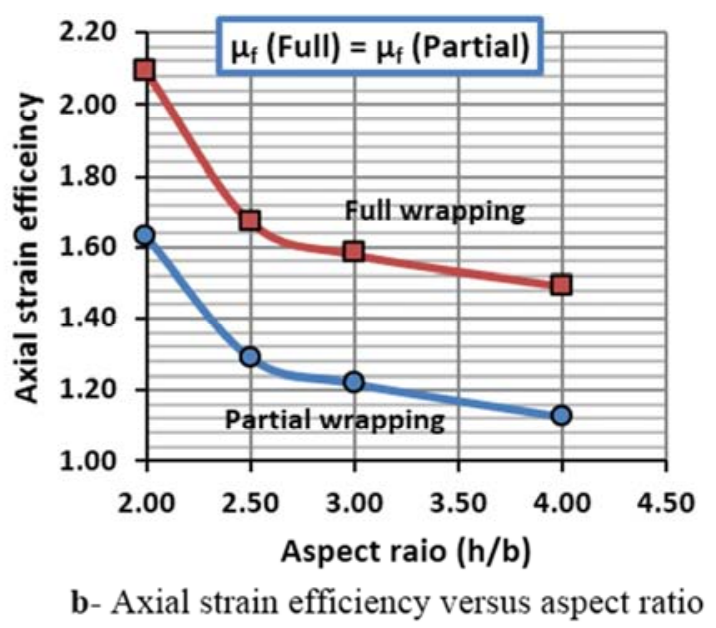

Figure 5. Effect of aspect ratio on gained strength and axial strain of different confined system.

\subsection{Axial Concrete Strain}

The FRP confinement effectiveness is more significant in terms of enhancement of concrete axial strain rather than the increase in axial strength. The strain improvement of FRP-confined capsule shape concrete columns with lower aspect ratio $(h / b<3)$ showed better enhancement more than columns with higher aspect ratio $(\mathrm{h} / \mathrm{b} \geq 3)$. By other words, the enhancement in confined axial strain decrease by increasing the cross-section aspect ratio of columns. The ratio $\frac{\varepsilon_{\mathbf{c c}}}{\varepsilon_{\mathbf{c o}}}$ (maximum axial strain $\varepsilon_{\mathbf{c c}}$ corresponding to the maximum axial stress of the confined column to their counterpart control unconfined column $\varepsilon_{\text {co }}$ at peak) is defined as axial strain efficiency factor; quantify the improvement in the axial strain and the enhancement in ductility of the columns due to confinement. For FRP-confined capsule shape columns, the axial strain efficiency factor $\left(\varepsilon_{\mathbf{c c}} / \varepsilon_{\mathbf{c o}}\right)$ of cross-sectional aspect ratio of 2 , $2.5,3$ and 4 , confined with one layer of CFRP sheet, were $2.06,1.61,1.58$ and 1.49 respectively. Also, for capsule shape columns confined with two layers of CFRP, the axial strain efficiency were equal to $2.56,2.01,1.89$ and 1.78 respectively. This proves that the transverse FRP confinement enhances the deformation characteristics of RC columns as well. Moreover, it is clear from Figure 6 that the axial strain efficiency factor decreased with increasing aspect ratios due to less confinement effect. The axial strain efficiency factor increased with increasing the number of layers of CFRP sheets from one layer to two layers: the axial strain efficiency factor was about 1.24 for lower aspect ratio $(\mathrm{h} / \mathrm{b} \leq 2.5)$, and about 1.20 for higher aspect ratio $(\mathrm{h} / \mathrm{b}>2.5)$.

For partially confinement system, the axial strain capacity decreased as aspect ratio increased, the axial strain efficiency factor $\left(\varepsilon_{\mathbf{c c}} / \varepsilon_{\mathbf{c o}}\right)$ were $1.65,1.29,1.26$ and 1.12 when aspect ratio $2,2.5,3$ and 4 respectively. Generally, the fully confined 
system showed a higher axial strain in comparison with the corresponding partially confined system with a same CFRP confinement ratio. The improvements in axial strain for one layer fully confined columns were $106 \%, 61 \%, 58 \%$ and $49 \%$; however, the improvements for partially confined ones were $65 \%, 29 \%, 26 \%$ and $12 \%$ when aspect ratios were $2,2.5,3$ and 4 respectively as shown in Table 3 and Figure (5-b).

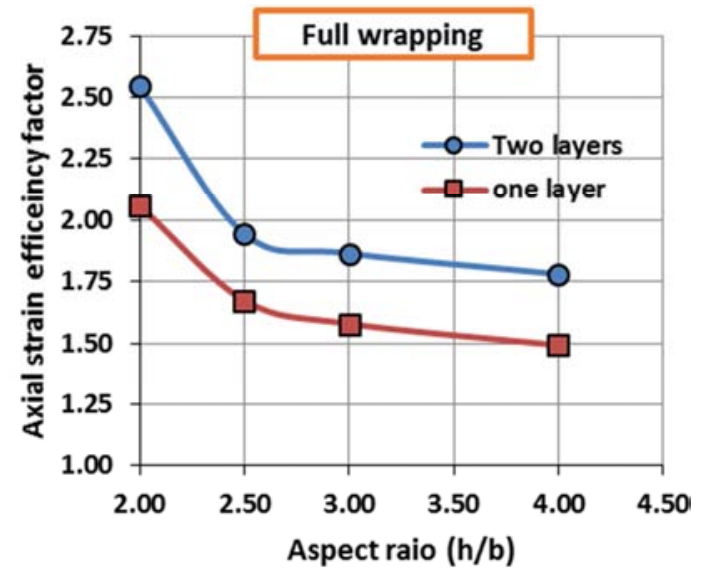

Figure 6. Effect of aspect ratio $(h / b)$ on axial strain efficiency factor.

Partially confined system showed a noticeable enhancement in concrete strain capacity $\varepsilon_{\mathrm{cc}}$ for capsule shape columns, specially, those of lower aspect ratios $(\mathrm{h} / \mathrm{b} \leq 2.5)$. In addition to being more ductile than unconfined columns, the failure behavior of the partially confined samples showed an alert and warning before occurrence of failure: the cracks begin to grow in the unconfined zones in comparison to fully confined columns, which failed suddenly without warning.

\subsection{FRP-hoop Strain}

The axial compressive behavior of the FRP-confined concrete is closely related to the confining pressure that the FRP jackets exert on the concrete. FRP-hoop strain at rupture of the confined columns is usually lower than the ultimate tensile strain. Throughout the different obtained results concerning the FRP-hoop strain, it is obvious that the maximum lateral or FRP hoop strains at failure $\varepsilon_{\text {fmax }}$ is less than the ultimate tensile strain $\varepsilon_{\text {fult }}(=1.8 \%)$ for the different confined columns.

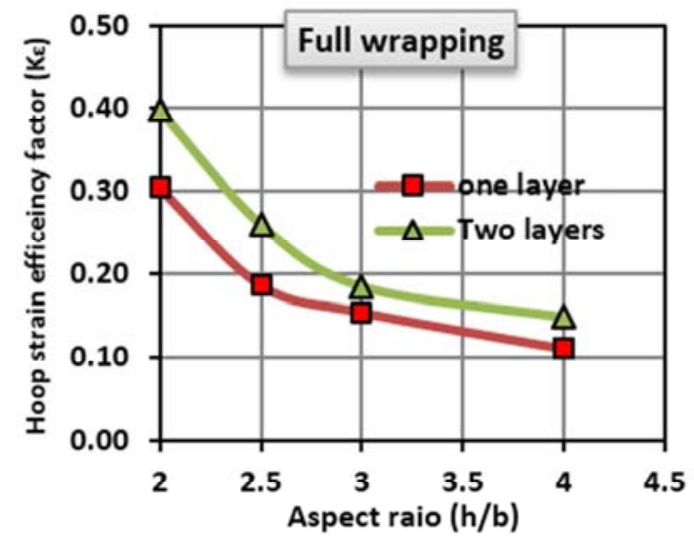

(a)
Moreover, the maximum hoop strains decreased as the cross-sectional aspect ratio increased, as shown in Table 3. From the present experimental results, summarized in Table 3 , the value of jacket efficiency factor $\left(\mathrm{K}_{\varepsilon}\right)$ of FRP-confined capsule shape columns ranges from $30 \%$ to $40 \%$ (35\% on average) for capsule shaped columns fully wrapped with one and two layers for the aspect ratio of $(h / b=2)$. For capsule shape fully wrapped columns, the jacket efficiency factor $\left(K_{\varepsilon}=\varepsilon_{\text {fmax }} / \varepsilon_{\text {fult }}\right)$ ranged decrease $19 \%$ to $26 \%$ (about 23 percent on average) for the aspect ratio of $(\mathrm{h} / \mathrm{b}=2.5)$, and about $17 \%$ for aspect ratio of $(\mathrm{h} / \mathrm{b}=3)$, and for the higher aspect ratio of $(\mathrm{h} / \mathrm{b}=4)$ only $13 \%$. The maximum hoop strain decreases as the aspect ratio $(\mathrm{h} / \mathrm{b})$ increases. Therefore, the maximum jacket efficiency factor $\left(K_{\varepsilon}\right)$ is related to the aspect ratio. Figures (7-a) \& (7-b) shows the relationship between aspect ratio $(h / b)$ and $\left(K_{\varepsilon}\right)$. It is evident that jacket efficiency factor is dependent on the confined system (full or partial system), thickness of the jacket, and the cross-sectional aspect ratio.

The observed FRP hoop strains at failure were always lower than the ultimate FRP strain determined from tensile tests. The ultimate FRP hoop strains at rupture differed for various column specimens, as shown in Figure 7. For fully confined capsule shape columns with aspect ratio $(\mathrm{h} / \mathrm{b}=2)$, the maximum hoop strain at failure was found as $5.48 \%$ o $(=$

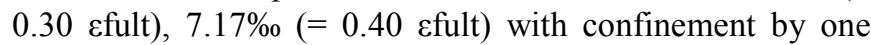
and two layers of CFRP sheets respectively, while this value decreased to $3.36 \%$ o (= 0.19 efult) and $4.69 \%$ (= 0.26 efult $)$ and less for capsule shape columns with a cross-sectional aspect ratio $(\mathrm{h} / \mathrm{b}>2.5)$. For a higher aspect ratio of 3 and 4 , the failure occurred at a much lower hoop- strains of $2.77 \%$ (=0.15 عfult) and $1.99 \%$ (=0.11 عfult) respectively.

Regardless the confined system (full or partial wrapping), the jacket efficiency factor $K_{\varepsilon}$ is inversely proportional to the cross section aspect ratio of the cross section: $K_{\varepsilon}$ decreases as the aspect ratio $(\mathrm{h} / \mathrm{b})$ increases. For fully FRP-confined columns with aspect ratio more than 3, slight increase was observed on the FRP hoop strain and the value of $k_{\varepsilon}$ was approximately equals 0.15 in average, while for partially FRP-confined columns with a cross-sectional aspect ratio more than 3 , the average value of $k_{\varepsilon}$ is decreased to 0.10 and less, see Figure 7.

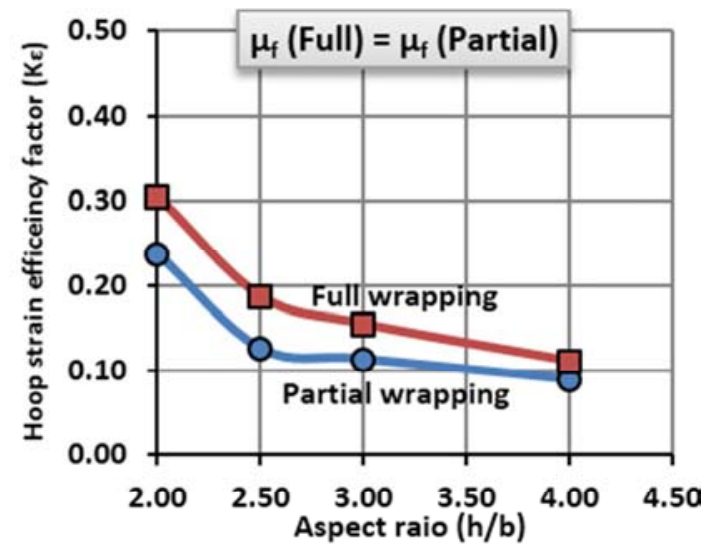

(b)

Figure 7. Effect of aspect ratio on the jacket efficiency factor $K_{\varepsilon}$ 
At the same level of loading, the FRP hoop strain increase as the number of layers decrease. However, the maximum hoop strain corresponding the maximum load normally increases as the number of layers increase, as long as the final failure due to rupture of FRP sheets: the failure mode for the different FRP-confined columns was due to the rupture of FRP sheets.

For certain FRP confinement ratio, the jacket efficiency factor $k_{\varepsilon}$ depends on the geometric of column's cross- sectional as the shape of cross-section, and aspect ratio, as showed in the previous studied and the experimental results in this study. Based on experimental results of CFRP-confined circular concrete columns by Lam and Teng [5], an average value of 0.586 was proposed for $k_{\varepsilon}$, and the value of 0.55 was recommended by ACI 440 2R-08 [1].Based on previous studies on FRP-confined square and rectangular concrete columns by [2-5] and [14], showed that the FRP jacket efficiency factor $k_{\varepsilon}$ decreases with the increasing cross-sectional aspect ratio. In addition, it was found that for square columns, the average value of $k_{\varepsilon}$ is equal to 0.40 while for rectangular columns with a cross-sectional aspect ratio of 2 and more the average value of $k_{\varepsilon}$ is reduced to 0.20 . Those average values of $k_{\varepsilon}$ were introduced into the model proposed by Tan et al, [11] and assumed that for any intermediate aspect ratio between 1 and 2, the FRP jacket efficiency factor $k_{\varepsilon}$ may be interpolated between 0.40 and 0.20 .

$\mathrm{Wu}$ and Wei [8], investigated the effects of the aspect ratio $(\mathrm{h} / \mathrm{b})$ on the FRP hoop strain, they showed that when the aspect ratio $(\mathrm{h} / \mathrm{b})$ varied from 1 to 2 , the FRP rupture strains at corners of rectangular sections were close together. Therefore, this study assumed that the effective failure strain of FRP is a function of the ratio of the corner radius and the shorter side length $(2 \mathrm{r} / \mathrm{b})$. Also, the effect of the aspect ratio for rectangular columns is accounted as shape factor of aspect ratio, which equal to $(h / b)^{-2.5}$. This shape factor includes the aspect ratio into their proposed model to reflect the variation of confinement effectiveness, which is different from all of the previous models.

Based on what mentioned previously concerning the FRP jacket efficiency factor $k_{\varepsilon}$, it is obvious that the efficiency factor $k_{\varepsilon}$ depends on various aspects and parameters, which their influence and interaction are difficult to be quantified analytically, the authors suggested expressions to predict the efficiency factor $k_{\varepsilon}$ as a functions of the geometry of cross-section as mentioned in Equations (1) to (4) and Figure 8.

For full wrapping

$$
\begin{gathered}
k_{\varepsilon}=\left(1-\left(\frac{h^{\prime \prime}}{4 b}\right)\right)\left(\frac{b}{h}\right) \text { for } \frac{h}{b} \leq 3 \\
k_{\varepsilon}=0.15 \text { for } \frac{h}{b}>3
\end{gathered}
$$

where $h^{\prime \prime}=h-2 r_{c}$

For partial wrapping

$$
\begin{gathered}
k_{\varepsilon}=\left(1-\left(\frac{h}{4 b}\right)\right)\left(\frac{b}{h}\right) \text { for } \frac{h}{b} \leq 2.5 \\
k_{\varepsilon}=0.10 \text { for } \frac{h}{b} \geq 3
\end{gathered}
$$

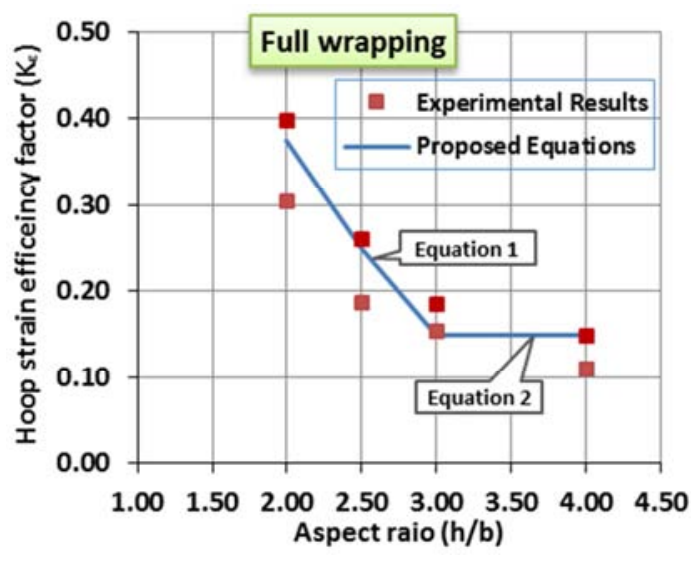

(a) Full wrapping.

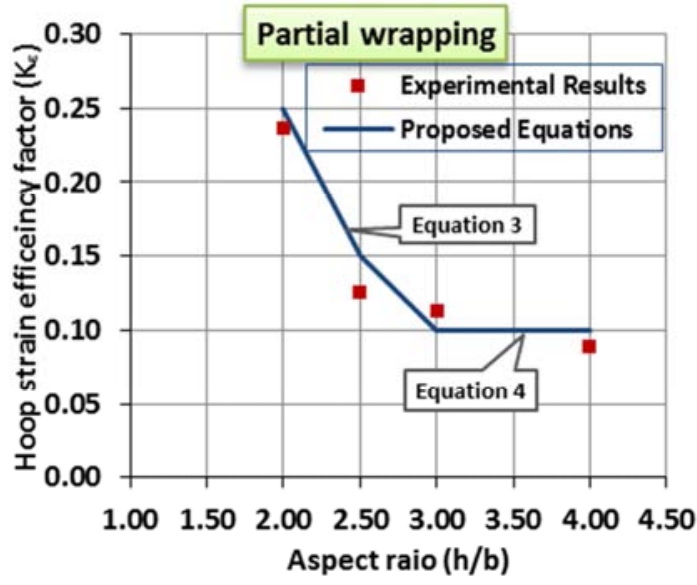

(b) Partial wrapping.

Figure 8. Experimental and proposed values of efficiency factor $(\mathrm{K \varepsilon})$.

\section{Analytical Modeling}

\subsection{Available Confining Model for Capsule Shape Columns}

According to the knowledge of the authors, So far there is only one available analytically model deals with FRP-confined capsule shape columns suggested by Tan et al, [11]. This model deals with fully confined capsule shape columns only. The ultimate axial load carrying $\left(P_{u}\right)$ depends on the confined concrete strength $\left(f_{c c}^{\prime}\right)$ which by its turn depends on the total confining presser $f_{l}^{*}$ and the concrete strength $f_{c}^{\prime}$, see Equation (5) and (6). The average lateral confining pressure $\left(f_{l}^{*}\right)$ is functional in both the geometry of cross section and the characteristic of used FRP and obtained according Equation (7).

$$
P_{u}=f_{c c}^{\prime} A_{C}
$$

in which, $A_{C}$ is the area of column.

$$
\begin{gathered}
\frac{f_{c c}^{\prime}}{f_{c}^{\prime}}=1+4.5 \frac{f_{l}^{*}}{f_{c}^{\prime}} \\
f_{l}^{*}=\frac{k_{e}}{2}\left(1+\frac{b}{h}\right)\left(\frac{2 n E_{f} t_{f} 0.2 \varepsilon_{f u l t}}{b}\right)
\end{gathered}
$$


where $\left(E_{f}\right)$ is the elastic modulus of wrapping FRP sheet in $\mathrm{N} / \mathrm{mm}^{2},(n)$ is the number of FRP layers, $\left(t_{f}\right)$ is the thickness of FRP sheet and $\left(\varepsilon_{u l t}\right)$ is the ultimate tensile strain of the FRP sheets.

The shape factor $\left(k_{e}\right)$ or the effective confinement of capsule shape and rectangular sections are given by:

$$
k_{e}=\frac{b h-(4-\pi) r_{c}^{2}-\frac{\left(b^{\prime 2}+h^{\prime 2}\right)}{3}}{b h-(4-\pi) r_{c}^{2}}
$$

where $b$ is the shorter dimension and $h "$ is the length of straight portion of the longer side of the cross-section, see Figures (11 \& 12).

The nominal compressive load was predicated according the analytical model suggested by Tan et al, [11]. The model showed an underestimation, where the values of the ratio of predicted load to that obtained experimentally $\left(P_{u \text { pre }(1)} / P_{u \text { exp }}\right)$ ranged from 0.737 to 0.965 , as shown in Table 5 and Figure 13. Moreover, the model does not deal with the FRP-confined capsule shape columns partially wrapped. Consequently, the authors proposed an analytical model take into account the effect of different encountered parameters into account, particularly those overlooked by the available model (Tan et al, [11]) particularly, those deals with partially confined columns and the level of confinement.

\subsection{Proposed Analytical Model}

The experimental results showed that the axial load carrying capacity of FRP-confined concrete columns improved considerably in comparison with the corresponding unconfined columns. The load carrying capacity of strengthened columns is affected by the confined concrete strength $\left(f_{c c}^{\prime \prime}\right)$, which by its turn is affected by both the level of confinement and the confined system (full or partial wrapping). The available model does not deal with the capsule shape columns confined with partial FRP sheets. Therefore, the authors proposed an analytical model take into account different parameters encountered when applying this technique. To predict the load carrying capacity of RC columns strengthened externally by means of wrapped CFRP sheets, the axial load carrying capacity of strengthened columns $\left(P_{u}\right)$ can be obtained according to Equation $(9)$ in a similar manner as the unstrengthen reinforced concrete columns.

$$
P_{u}=\beta f_{c c}^{\prime \prime} A_{c}+f_{y} A_{s}
$$

where $A_{c}$ is the area of the section concrete column, $A_{s}$ is the area of longitudinal reinforcement, $f_{y}$ is the yield stress of the longitudinal reinforcement, $\beta$ is a factor depends on the level of confinement as given by Rocca et al. [15], which by its turn depends on the FRP confinement ratio, shape of cross section and cross sectional aspect ratio of the columns as shown in Figure 9.

$\beta=0.85$ For capsule shape with $(\mathrm{h} / \mathrm{b}<3)$

$\beta=0.80$ For capsule shape with $(\mathrm{h} / \mathrm{b} \geq 3)$

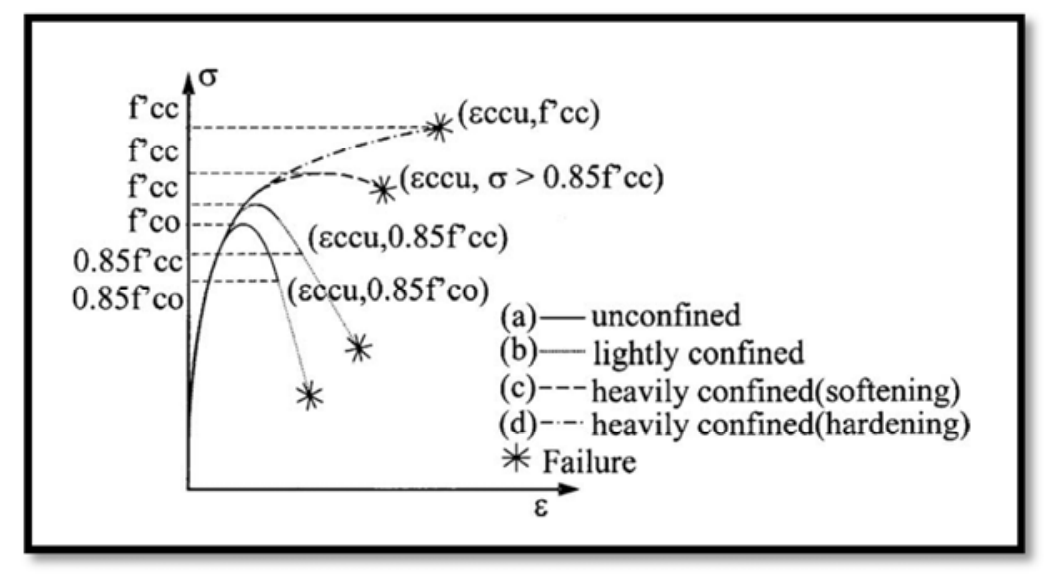

Figure 9. Schematic stress-strain behavior of confined and unconfined RC columns (Rocca et al., [15]).

The confined concrete strength $\left(f_{c c}^{\prime}\right)$ herein is predicted according to Equation (10) originally proposed by Mander et al. (1988a).

$$
f_{c c}^{\prime}=f_{c}^{\prime}\left(2.254 \sqrt{1+\frac{7.94 f_{l}^{*}}{f_{c o}^{\prime}}}-2 \frac{f_{l}^{*}}{f_{c}^{\prime}}-1.254\right)
$$

where $\left(f_{c}^{\prime}\right)$ is the unconfined standard cylinder compressive strength of concrete $\left(f_{c}^{\prime}=0.8 f_{c u}\right), f_{c u}$ is unconfined standard cube compressive strength of concrete.

To calculate the confining pressure $f_{l}$, it is necessary to consider that the capsule shaped section is consists of two semi-circular segments and a rectangular segment in between, as shown in Figure 10. The lateral confining pressure assumed to be uniformly distributed along the longitudinal axis of the column. The equilibrium of forces gives the maximum lateral confining pressure $\left(f_{l}\right)$ as:

$$
f_{l}=\frac{2 n_{f} t_{f} E_{f} \varepsilon_{u l t}}{b}\left(\frac{b_{f}}{b_{f}+s^{\prime}}\right)
$$

where $(b)$ is the shorter side of column's cross section, $\left(E_{f}\right)$ is the elastic modulus of wrapping FRP sheet in N/mm,$\left(n_{f}\right)$ is the number of FRP layers, $\left(t_{f}\right)$ is the effective thickness of FRP sheet and $\left(\varepsilon_{u l t}\right)$ is the ultimate tensile strain of the FRP sheets.

The term $\left(b_{f} /\left(b_{f}+s^{\prime}\right)\right)$ deals with type of confinement (partially or fully confined): for partially confined $b_{f}$ is the width of FRP strip and $s^{\prime}$ is the free spacing between FRP 
strips, (Figure 13), for fully confined the term $\left(b_{f} /\left(b_{f}+\right.\right.$ $\left.\mathrm{s}^{\prime}\right)$ ) is equal to 1.0. The lateral confining pressure of FRP-confined capsule shape columns $\left(f_{l}^{*}\right)$ can be calculated according to Equation (12).

$$
f_{l}^{*}=f_{l} \times\left(k_{\varepsilon} \times k_{e} \times k_{p}\right)
$$

The efficiency factors $k_{e}, k_{p}$ and $k_{\varepsilon}$ introduced in Equation (12) deal with the effective confined area due to the shape of cross-section, the type of confinement (full or partial wrapping), and the jacket efficiency factor respectively.
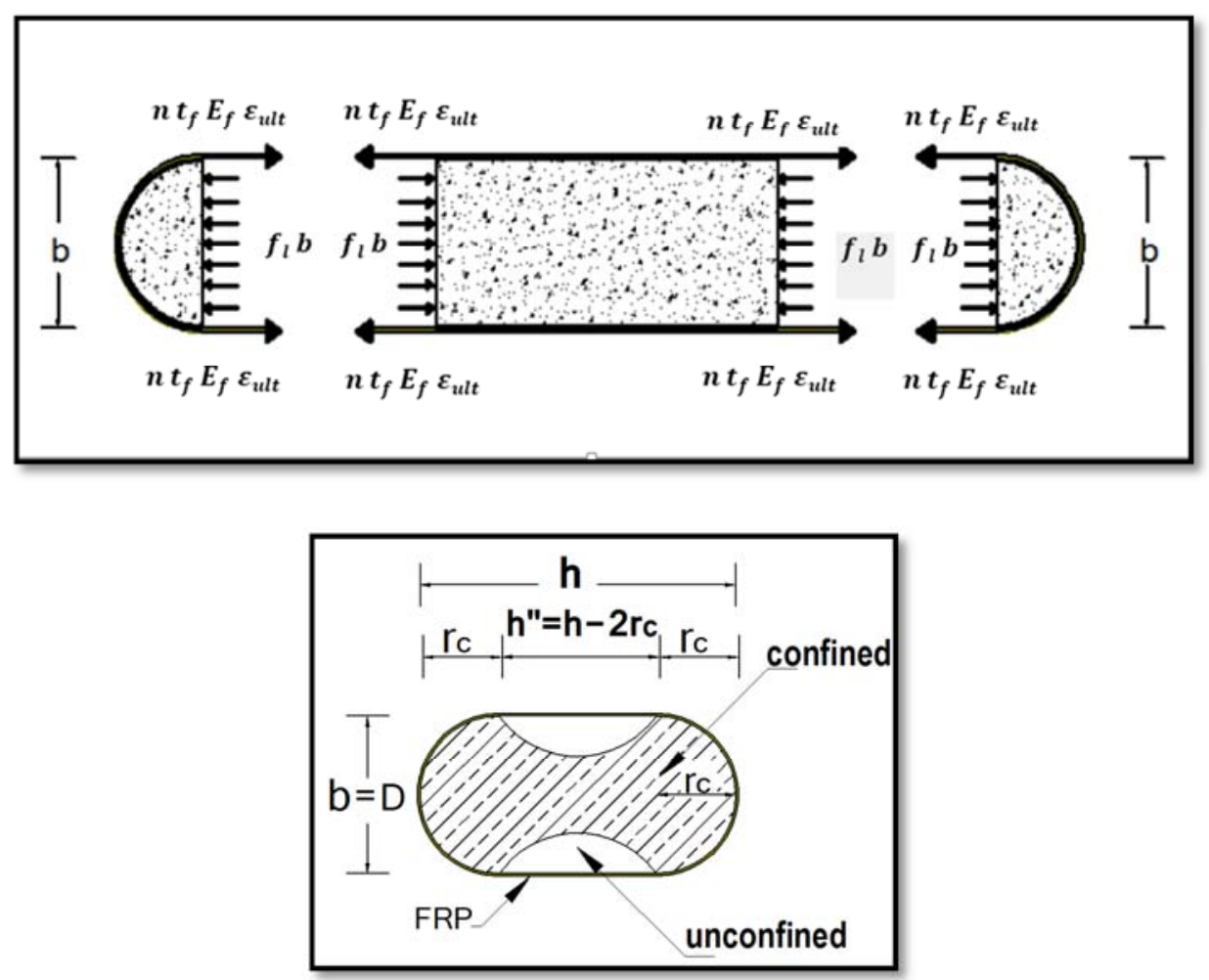

Figure 10. Confinement model for a capsule shaped columns.

The FRP-jacket efficiency factor $\left(k_{\varepsilon}\right)$ depends on the geometric of column's cross section (the aspect ratio) for the same FRP confinement ratio. $k_{\varepsilon}$ is calculated as suggested by the authors previously, see Equations (1) to (4) for full and partial wrapping. The shape factor $\left(k_{e}\right)$ or the effective confinement coefficient is defined as the ratio of effectively confined concrete core area $\left(A_{e}\right)$ to the total area of concrete column $\left(A_{c}\right), k_{e}\left(=A_{e} / A_{c}\right)$. The capsule-shaped column is considered as a rectangular column of area $(b h)$ with corner radius $r_{c}$ as shown in Figure 11, the total concrete area $\left(A_{c}\right)$ of the capsule-shaped column is given according to Equation (13).

$$
A_{c}=b h-4\left[r_{c}^{2}-\frac{\pi r_{c}^{2}}{4}\right]=b h-[4-\pi] r_{c}^{2}
$$

Due to the lateral confining, the semi-circular segments of the capsule-shaped column are considered fully confined while the rectangular segment is partially confined. It is commonly accepted that, in a rectangular section, only part of the concrete is effectively confined by lateral FRP sheets through the arching action. However, for capsule-shaped column, the effective confinement area is contained by two parabolas, with the initial slopes of the parabolas being the same as the adjacent diagonal lines. The effective area $\left(A_{e}\right)$ is obtained by subtracting the unconfined area of parabolas assumed by arching action from the total area $\left(A_{c}\right)$ as shown in Figure 11, where the area of one parabola is equal to $\left(\left(\mathrm{h}^{\prime \prime}\right)^{2} / 6\right)$. Consequently, the effective confined area $\left(A_{e}\right)$ of both rectangular and capsule-shaped sections can be calculated according Equation (14), see Figure 11.

$$
A_{e}=A_{c}-2\left(\frac{b^{\prime 2}+h^{\prime 2}}{6}\right)=b h-[4-\pi] r_{c}^{2}-\left(\frac{b^{\prime 2}+h^{\prime 2}}{3}\right)
$$

As a result, the general formula of the effective confinement coefficient of rectangular and capsule-shaped sections are given according Equation (15).

$$
k_{e}=\frac{A_{e}}{A_{c}}=\left[1-\left(\frac{b^{\prime 2}+h^{\prime 2}}{3\left(b h-[4-\pi] r_{c}^{2}\right)}\right)\right]<1
$$

For rectangular section $\left(b^{\prime \prime}=b-2 r_{c}\right)$ and $\left(h^{\prime \prime}=h-\right.$ $\left.2 r_{c}\right)$. For capsule-shaped section $b^{\prime \prime}=0$ since $\left(b=2 r_{c}\right)$ and $\left(h^{\prime \prime}=h-b\right)$ for two arches along the straight portion of the longer side section in plan with an initial tangent slope of $45^{\circ}$ but, for rectangular section four arches along the four sides, as shown in Figure 12.

The effective confinement coefficient of capsule-shaped sections can be written as:

$$
k_{e}=\frac{A_{e}}{A_{c}}=\left[1-\left(\frac{(h-b)^{2}}{3\left(b h-[4-\pi] r_{c}^{2}\right)}\right)\right]<1
$$




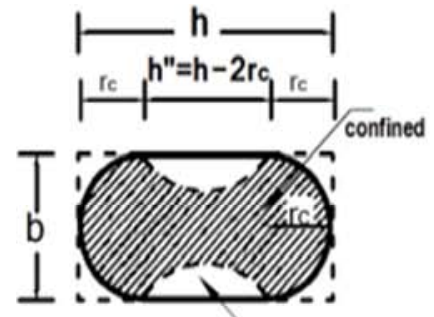

$h / b<3$ unconfined

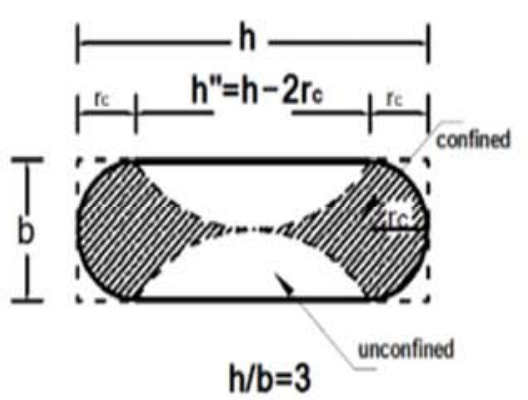

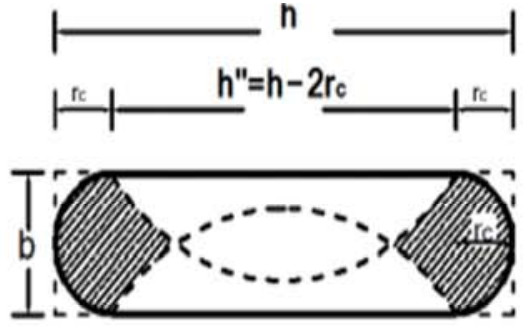

$h / b>3$

Figure 11. Proposed confinement model for capsule-shaped columns.

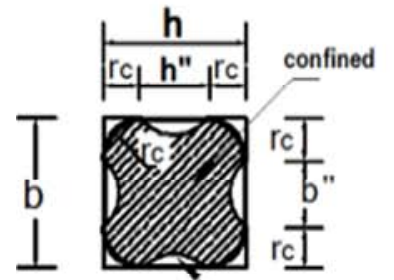

$\mathrm{h} / \mathrm{b}<2$ unconfined

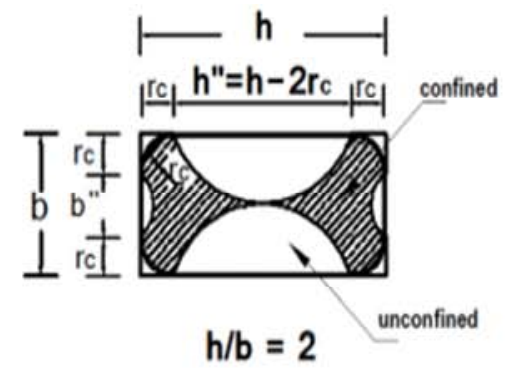

Figure 12. Confinement model for rounded corners rectangular columns.
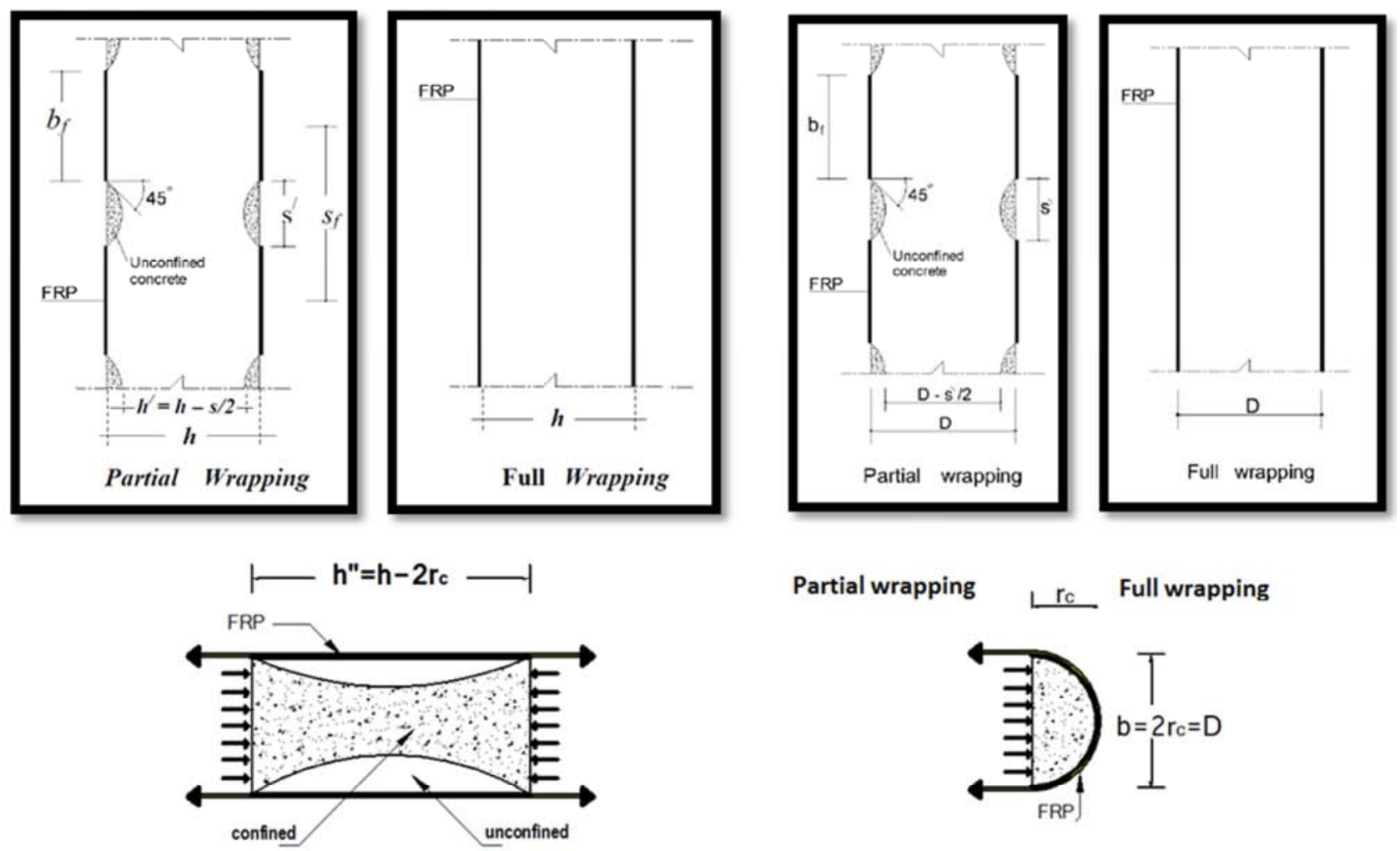

a- Rectangular segment

b- Circular segment

Figure 13. Confining pressure on a capsule-shaped column wrapped by FRP sheet.

For partial wrapping, the effective confining pressure is assumed to be exerted effectively on the part of the concrete core where the confining pressure has fully developed due to the arching action. A second-degree parabola with initial slope of $45^{\circ}$ is assumed to describe the arching effect, as shown Figure 13. In such a case, a confinement effective coefficient $k_{p}$ is introduced to consider the partial wrapping as follows: 


$$
\begin{gathered}
k_{p}=\frac{A_{e c a p}}{A_{c}} \\
A_{c}=b^{\prime \prime} h^{\prime \prime}+\frac{\pi D^{2}}{4} \\
A_{\text {e cap }}=\left(b^{\prime \prime} h^{\prime \prime}+\frac{\pi D^{2}}{4}\right)-\left(b^{\prime \prime} h^{\prime \prime}\left(\frac{s^{\prime} / 2}{\left(h-2 r_{c}\right)}\right)+\frac{\pi\left(s^{\prime} / 2\right)^{2}}{4}\right) \\
A_{\text {e cap }}=b h^{\prime \prime}\left(1-\frac{s^{\prime} / 2}{h^{\prime \prime}}\right)+\frac{\pi D^{2}}{4}\left(1-\left(\frac{s^{\prime} / 2}{D}\right)^{2}\right) \\
A_{\text {e Cap }}=A_{\text {e Rec }}+A_{\text {e Cir }}
\end{gathered}
$$

where $A_{e \text { Cap }}$ is the effective area of capsule shape section, $A_{e \text { Rec }}$ the effective area of rectangular section and $A_{e \text { Cir }}$ the effective area of circular section.

For partial wrapping:

$$
k_{p}=\frac{A_{e c a p}}{A_{c}}=\frac{b h^{\prime \prime}\left(1-\frac{s^{\prime}}{2 h^{\prime \prime}}\right)+\frac{\pi}{4}\left(D-\frac{s^{\prime}}{2}\right)^{2}}{\left(b h^{\prime \prime}+\frac{\pi D^{2}}{4}\right)}<1
$$

For Full wrapping:

$$
k_{p}=1
$$

\subsection{Analytical Verification of the Proposed Model}

The Proposed analytical models for capsule shape reinforced concrete columns described in the previous section were assessed by comparing the predicated values with corresponding experimental results. The experimental results obtained through this study was used to evaluate the analytical models, and the average ratios between predicated and experimental load carrying capacity, the coefficients of variation, and the correlation factor were calculated to evaluate the performance of the analytical models.

The predicted load carrying capacity of the tested capsule shape columns $\left(P_{u \text { pre }}\right)$ was calculated according to model proposed by authors, assuming that $\beta=0.85$ for aspect ratio $(h / b<3)$ and $\beta=0.80$ for aspect ratio $(h / b \geq 3)$, see Table 4 . The predicted values were compared with the those obtained experimentally for the different tested columns, as shown in Table 4. It is worth to note that, the proposed model showed a good estimation and approached considerably to the experimental results (Table 4). It is found that an excellent estimation to the experimental results for fully and partially confined capsule shape columns was achieved correlation factor equals 0.987 and low standard deviation of $3.984 \%$ and coefficient of variation of 3.91 .

The predicted axial load carrying capacities of FRP-confined capsule shape columns was calculated by the model proposed by Tan et al, [11] and compared with the corresponding obtained experimental results, as shown in Table 5. The standard deviation and correlation factor were $8.533 \%$ and 0.944 respectively. The comparison of proposed confinement model and Tan et al, [11] model with the observed results were presents in Figure 14.

Both analytical models predicted the axial load capacity reasonably well, particularly in case of that proposed by authors, which showed a better estimation approaching to the experimental results (see Table 5). Considerably, it can be noticed that, the errors in predicting the axial load capacity were maximum for columns with aspect ratio $(\mathrm{h} / \mathrm{b}=4)$ by the proposed model while minimum errors occurred for aspect ratio $(\mathrm{h} / \mathrm{b}<4)$ in case of model suggested by Tan et al, [11]. Thus, the model proposed by Tan et al, [11] is underestimation for various section aspect ratios except equals 4. It is

\begin{tabular}{|c|c|c|c|c|}
\hline \multirow{2}{*}{ Column No. } & \multirow{2}{*}{$\begin{array}{l}\text { Experimental results } \\
P_{u \exp }(\mathrm{KN})\end{array}$} & \multicolumn{2}{|c|}{ Predicated results by proposed model $\boldsymbol{P}_{u, p r e}(\mathrm{KN})$} & \multirow{2}{*}{$\frac{\boldsymbol{P}_{\text {upre }}}{\boldsymbol{P}_{\text {uexp }}}$} \\
\hline & & $\beta=0.85$ & $\beta=0.80$ & \\
\hline B0-2 & 1155 & 1112 & & 0.962 \\
\hline BP-2 & 1414 & 1429 & & 1.011 \\
\hline BF1-2 & 1658 & 1635 & & 0.986 \\
\hline BF2-2 & 1959 & 2044 & & 1.044 \\
\hline B0-2.5 & 1425 & 1423 & & 0.999 \\
\hline BP-2.5 & 1655 & 1695 & & 1.024 \\
\hline BF1-2.5 & 1884 & 1859 & & 0.987 \\
\hline BF2-2.5 & 2175 & 2228 & & 1.025 \\
\hline B0-3 & 1651 & & 1659 & 1.004 \\
\hline BP-3 & 1816 & & 1884 & 1.037 \\
\hline BF1-3 & 2043 & & 1980 & 0.969 \\
\hline BF2-3 & 2326 & & 2266 & 0.974 \\
\hline B0-4 & 2146 & & 2254 & 1.050 \\
\hline BP-4 & 2255 & & 2475 & 1.098 \\
\hline BF1-4 & 2399 & & 2509 & 1.046 \\
\hline BF2-4 & 2523 & & 2738 & 1.085 \\
\hline Average & & & & 1.019 \\
\hline Standard devia & & & & 3.984 \\
\hline Coefficient of & & & & 3.910 \\
\hline Correlation fac & & & & 0.987 \\
\hline
\end{tabular}
interesting to mention that, proposed model is found an excellent estimation to the experimental results for fully confined capsule shape columns with excellent correlation factor of 0.989 and lower standard deviation of $3.86 \%$ and lower coefficient of variation of 3.821 .

Table 4. Experimental and predicted load capacity based on proposed model. 
Table 5. Experimental and predicted load capacity based on proposed model and model proposed by Tan et al, [11].

\begin{tabular}{|c|c|c|c|c|c|}
\hline \multirow{3}{*}{ Column No. } & \multirow{3}{*}{$\begin{array}{l}\text { Experimental results } \\
P_{u} \exp (\mathrm{KN})\end{array}$} & \multicolumn{4}{|c|}{ Predicted results $(\mathrm{KN})$} \\
\hline & & \multicolumn{2}{|c|}{ Proposed model } & \multicolumn{2}{|c|}{ Model proposed by Tan et al, [11] } \\
\hline & & $P_{\text {upre }}$ & $\frac{P_{\text {u pre }}}{P_{\text {u exp }}}$ & $P_{u p r e(1)}$ & $\frac{P_{u \text { pre }(1)}}{P_{u \text { exp }}}$ \\
\hline B0-2 & 1155 & 1112 & 0.962 & 970 & 0.840 \\
\hline BF1-2 & 1658 & 1635 & 0.986 & 1222 & 0.737 \\
\hline BF2-2 & 1959 & 2044 & 1.044 & 1461 & 0.746 \\
\hline B0-2.5 & 1425 & 1423 & 0.999 & 1242 & 0.872 \\
\hline BF1-2.5 & 1884 & 1859 & 0.987 & 1516 & 0.805 \\
\hline $\mathrm{BF} 2-2.5$ & 2175 & 2228 & 1.025 & 1773 & 0.815 \\
\hline B0-3 & 1651 & 1659 & 1.004 & 1514 & 0.917 \\
\hline $\mathrm{BF} 1-3$ & 2043 & 1980 & 0.969 & 1796 & 0.879 \\
\hline BF2-3 & 2326 & 2266 & 0.974 & 2058 & 0.885 \\
\hline B0-4 & 2146 & 2254 & 1.050 & 2058 & 0.959 \\
\hline $\mathrm{BF} 1-4$ & 2399 & 2509 & 1.046 & 2316 & 0.965 \\
\hline BF2-4 & 2523 & 2738 & 1.085 & 2547 & 1.010 \\
\hline \multicolumn{2}{|l|}{ Average } & & 1.011 & & 0.869 \\
\hline \multicolumn{2}{|c|}{ Standard deviation (\%) } & & 3.863 & & 8.533 \\
\hline \multicolumn{2}{|c|}{ Coefficient of variation } & & 3.821 & & 9.818 \\
\hline \multicolumn{2}{|c|}{ Correlation factor } & & 0.989 & & 0.944 \\
\hline
\end{tabular}

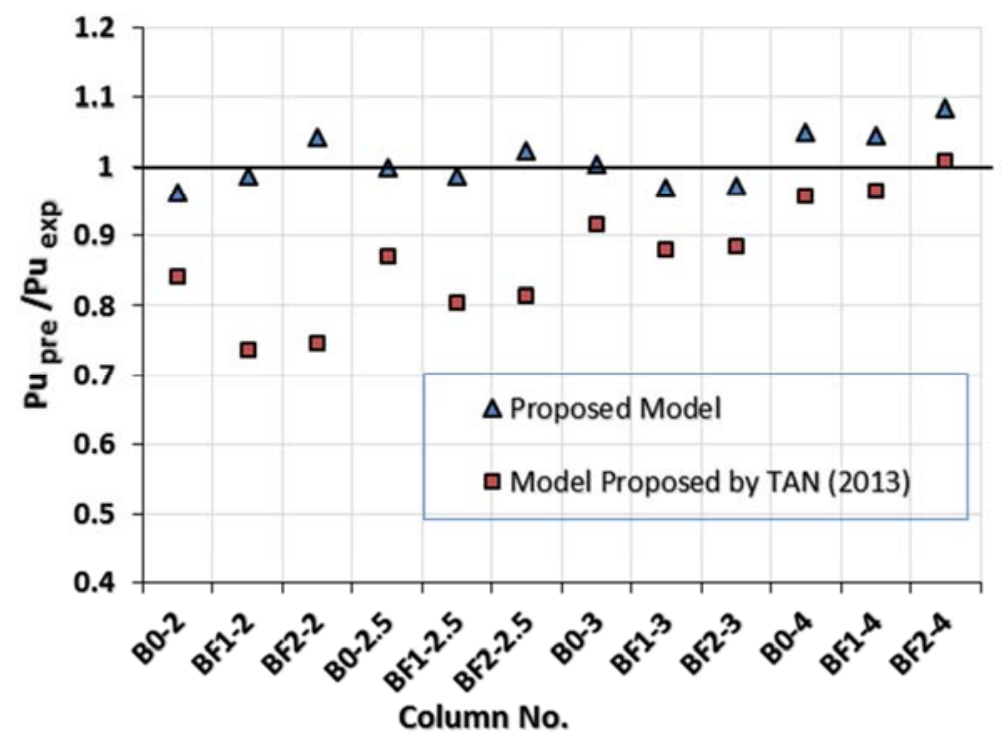

Figure 14. Performance of capsule-shaped confinement models.

\section{Conclusion}

Based on the conducted experimental tests on the axially loaded capsule- shaped FRP-confined columns with large-scale and higher aspect ratio as well as the performed analytical verification, the following conclusions may be drawn out:

1. Significant enhancement in axial load capacities and axial strain efficiency were observed for FRP-confined capsule shape columns, particularly in case of full wrapping and higher FRP confinement ratio.

2. The enhancement in confined strength and axial strain efficiency decrease by increasing the cross-sectional aspect ratio of capsule shape columns.

3. The gained strength are inversely proportional to a cross-sectional aspect ratio and direct proportional with the FRP confinement ratio. FRP-confined columns with higher section aspect ratios $(\mathrm{h} / \mathrm{b}>3)$ showed a slight increase in compressive strength and axial strain.

4. Partially FRP-confined capsule shape columns showed a noticeable enhancement in concrete strain capacity particularly in case of aspect ratio equal to and smaller than $2.5(\mathrm{~h} / \mathrm{b} \leq 2.5)$.

5. The max hoop strain corresponding to the maximum load decreases as the aspect ratio $(\mathrm{h} / \mathrm{b})$ increases. Therefore, the maximum jacket efficiency factor $\left(k_{\varepsilon}\right)$ is proportional to the aspect ratio.

6 . The analytical model proposed by the authors to predict the load carrying capacity of fully and partially FRP-confined capsule shape columns showed a good estimation and approaches considerably to results obtained experimentally, with correlation factor and the coefficient of variation equal to 0.987 and $3.91 \%$ respectively.

7. Both of the analytical models (by authors and by Tan et 
al, (2013)) predicted the axial load capacity for fully FRP-confined capsule shape columns reasonably well, particularly in case of that proposed by authors, which showed a better estimation approaching considerably to the experimental results.

\section{References}

[1] ACI Committee 440 (2008), Guide for the design and construction of externally bonded FRP systems for strengthening concrete structures, (ACI 440. 2R-08 (2008)), American Concrete Institute, Farmington Hills, MI.

[2] Chaallal, O., Shahawy, M., Hassan, M. (2003), Performance of axially loaded short rectangular columns strengthened with Carbon fiber-reinforced polymer wrapping, J. of Compos. Constr., 7(3), 200-208.

[3] Harajli, M. H. (2006), axial stress-strain relationship for FRP confined circular and rectangular concrete columns, Cement \& Contraction Composites, 28, 938-948.

[4] Ilki A, Peker O, Karamuk E, Demir C, Kumbasar. N, (2008), FRP retrofit of low and medium strength circular and rectangular reinforced concrete columns, J Mater Civil Eng. 20(2):169-188.

[5] Lam L and Teng JG (2003a), Design-oriented stress-strain model for FRP-confined concrete in rectangular columns, Journal of Reinforced Plastics and Composites 22(13): 11491186.

[6] Rochette, P.; Labossiere, P. (2000), Axial testing of rectangular columns models confined with composites, Journal of Composites for Construction, ASCE, vol. 4, no. 3, pp. 129-136.

[7] Tao, Z \& Zhong YZ, (2008), Compressive behaviour of CFRP-confined rectangular concrete columns. Magazine of Concrete Research, vol. 60, no. 10, pp. 735-745.
[8] Wu, Y.-F. and Y.-Y. Wei, (2010), Effect of cross-sectional aspect ratio on the strength of CFRP-confined rectangular concrete columns, Engineering Structures 32(1): 32-45.

[9] Triantafillou TC, Choutopoulou E, Fotaki E et al. (2016), FRP confinement of wall like reinforced concrete columns, Materials and Structures 49(1): 651-664.

[10] Saravanan S, Sakthieswaran N, Shiny Brintha G, (2015), A Study on Hybrid FRP Wrapped Axially Loaded RC Capsule Column, International Journal of Research in Advent Technology, Vol. 3, No. 6, June.

[11] Tan K. H, T. Bhowmik, et al (2013), Confinement model for FRP-bonded capsule-shaped concrete columns, Engineering Structures 51, 51-59.

[12] SIKA (2006); Technical Report: Prouduct Data Sheet, Edition 2006.

[13] Megahid A., Farghal Omar A., Mohamed M., and Bazar W., (2018), Effect of Cross-Sectional Aspect ratio on the Behavior of CFRP-Confined Rectangular Reinforced Concrete Columns, Proceedings of the Second International Conference on Multidisciplinary Research (ICMR), Faculty of Science, Assiut University, Assiut, Egypt, 28-30 January.

[14] Wang, Lei-Ming and $\mathrm{Wu}, \mathrm{Yu}$ Fei (2008), Effect of corner radius on the performance of CFRP-confined square concrete columns, Engineering Structures, 30, 493-505.

[15] Rocca S, Galati N and Nanni A (2008), Experimental evaluation of non-circular reinforced concrete columns strengthened with CFRP, ACI Structural Journal 258(SP3): $37-56$.

[16] Mander, J. B., Priestley, M. J. N., and Park, R. (1988a), Observed Stress-Strain Behaviour of Confined Concrete, Journal of Structural Engineering, 114(8), 1827-1849. 